\title{
Chemical Structure of Kerogen of Shale Formations (By the Example of the Shale Formations of the East European Platform)
}

\author{
R. N. MUSTAEV, M. V. ZAKHARCHENKO, L. I. KERIMOVA and I. M. SALIHOVA \\ Russian State Geological Prospecting University, 23 Miklouho-Maclay, Moscow, Russian Federation, \\ *Corresponding author E-mail: r.mustaev@ mail.ru, m.zaxarchenko@ inbox.ru, \\ vagif.kerimov@mail.ru, irina.dlspiyi@mail.ru \\ http://dx.doi.org/10.13005/ojc/340512
}

(Received: May 06, 2018; Accepted: August 23, 2018)

\begin{abstract}
The article deals with the chemical structure of kerogen and its transformation in catagenesis of shale formations by the example of the Middle Volga shale formations and the Domanic carbonaceous deposits of the East European Platform. The studies allowed identifying the main distinctive features in the structure of individual structural components of these types of kerogen and refining the models of the fragment of their chemical structure. Some of the oxygen-containing structures are found to be present in the Middle Volga kerogen as carbohydrate moieties and algaenan components, the alkyl chains in which are interlinked by ether bonds, and the structure of the sulfur-containing components can be represented as sulfide (polysulfide) bound n-alkyl structures, in pyrolysis of which low-molecular and high-molecular alkyl-substituted thiophenes, thienyl- and phenylthiophenes are formed. The average S/C value exceeding 0.04 classifies the Upper Jurassic kerogen as Type II-S. The predominant components constituent in the composition of kerogen of Domanic rocks are lipid components, however, its lower aliphaticity is probably due to the higher maturity of organic matter $(\mathrm{OM})$ and to the low ratio of $n$-alkyl structures to polyaromatic moieties, the formation of which is connected with the rearrangement of polyene and heteroatomic structures in catagenesis.
\end{abstract}

Keywords: Kerogen, Transformation, Catagenesis, Shale formations,

Eastern European Platform, Organic matter.

\section{INTRODUCTION}

Kerogen, which is the most important source of hydrocarbons, is one of the main objects of organic geochemistry. The term "kerogen" is understood to mean all OM of sedimentary rocks (oil shales and dispersed OM of any genetic type which is syngenetic to rock), insoluble in conventional organic solvents. The main chemical elements that form the structure of the kerogen are carbon, hydrogen and oxygen, and also nitrogen and sulfur at lower concentrations. The hydrogen enrichment of kerogen indicates significant oil-generating properties of OM of sedimentary rock; the increased 
content of heterogeneous elements in its structure decreases hydrocarbon generation in catagenesis and contributes to the formation of predominantly low molecular heteroatom compounds (water, carbon dioxide, etc.). Consequently, the elemental composition of the $\mathrm{OM}$ is one of the necessary characteristics of kerogen of different genetic types and catagenetic maturation in the analysis of oil-generating properties of the organic matter ${ }^{1,2}$.

\section{Research methodology}

Gas chromatographic analysis of the hydrocarbon fraction of bitumoids was performed using a Crystal-2000M gas chromatograph equipped with a 30 m long SPB-1 (Supelco) capillary column with an internal diameter of $0.32 \mathrm{~mm}$; the thickness of a fixed phase was $0.25 \mu \mathrm{m}$. The temperature of the column thermostat was programmed in the range from 110 to $300^{\circ} \mathrm{C}$ with a rate of $5^{\circ} \mathrm{C}$ per minute. The temperature of the injector was $300^{\circ} \mathrm{C}$, that of the detector was $300^{\circ} \mathrm{C}$. Benzene was used as a solvent. The carrier gas was helium.

Chromato-mass-spectral analysis was performed using Shimadzu QP5050A mass spectrometer. For chromatographic separation, we used a DB-1 column (30m* $0.25 \mathrm{~mm})$; the thickness of the stationary phase was $0.25 \mu \mathrm{m}$. Chromatography was performed in the temperature programming mode in the range from 50 to $300^{\circ} \mathrm{C}$ with a rate of $5^{\circ} \mathrm{C}$ per minute. The temperature of the injector was $300^{\circ} \mathrm{C}$, that of the ionic source was $250^{\circ} \mathrm{C}$. The sample injection was a split injection $(1: 30)$, the sample volume was $1 \mu \mathrm{l}$. We used a quadrupole mass spectrometer with ionization energy of $70 \mathrm{eV}$.

Rock-Eval pyrolysis was performed using a Rock-Eval 6 Standart device from Vinci Technologies.

The elemental analysis of kerogen was performed using EA 1110 (CHNS-O) CE Instruments Element Analyzer.

\section{Study Results and Discussion}

Structural features of kerogen of shale formations. The structural features of kerogen are defined, primarily, by the type of the starting OM, and by the diagenetic processes in the sedimentation environment. The structure of kerogen is formed in deposits at low temperatures and pressure, and the resulting polycondensed substance is metastable under these conditions ${ }^{3}$. As a result, the initial composition of the geopolymer can be preserved even in ancient sedimentary rocks, unless these rocks were at great depths (ibid.). Immature kerogen can be considered as a mixture of various macromolecular structures comprising destructionresistant biomacromolecules and recombined biodegradation products in unknown proportions. During the maturation of $\mathrm{OM}$, continuous changes will occur in the composition of the geopolymer to result, primarily, in the formation of a chemical structure resistant to further destruction. There have been few attempts to diagram the chemical structure of kerogen ${ }^{3-8}$. The authors of a number of papers proposed fragments of the chemical structure of kerogen and chemical formulas simulating the kerogen structure of kukersite ${ }^{8}$, oil shales of the Green River and other formations ${ }^{5,7}$.

The best-studied objects in terms of structural-molecular simulating are the kerogenes of the oil shales of the Green River formation (Eocene) and the kukersite (Middle Ordovic). The study was based on oxidative processes with various reagents - potassium permanganate, chromic acid, nitric acid, ozone and other oxidants. A. Burlingame and B. Siemoneit ${ }^{4}$.

Considering the features of possible types of kerogen, French geochemists F. Bekha and M. Vandenbrook offered their model of the chemical structure of geopolymers dated to different stages of thermal evolution ${ }^{5}$. The construction is based on information on the atomic composition of the kerogens under study, atomic groups comprising the closest chemical environment, which is based on the use of elemental analysis methods, solid-state ${ }^{13} \mathrm{C}$ NMR spectroscopy (nuclear magnetic resonance spectroscopy), XANES and other physical and chemical research methods. For example, the structure of Type II kerogen was proposed using the results of studies of the kerogen of the Toarcian shales at the Paris Basin Figure 1. 


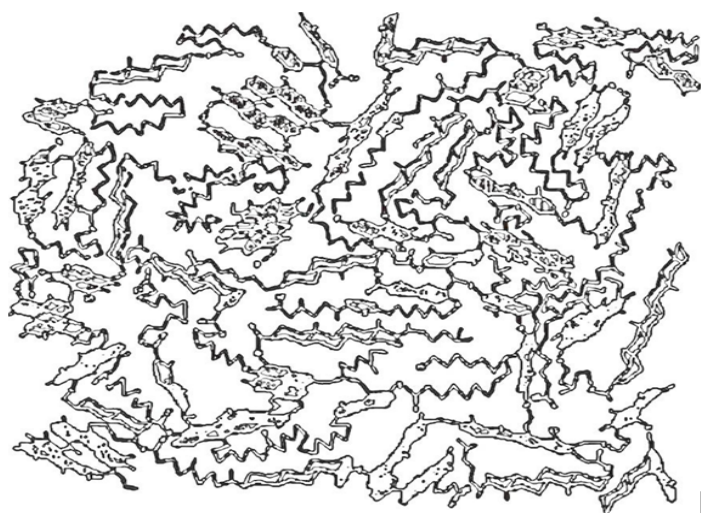

Fig. 1. Model of the chemical structure of Type II kerogen - beginning of catagenesis (the kerogen of the Toarcian oil shales of the Paris Basin)

The papers of Estonian researchers focused on the chemical structure of kerogen of kukersite allowed constructing a moiety of the geopolymer, confirming the offered structure using the simulation of C MAS NMR spectrum ${ }^{8}$. The constructing of the chemical structure of this kerogen was based on the detailed studies of Estonian geochemists ${ }^{9}$, joint studies on the composition of kerogen by Dutch and French scientists ${ }^{10-12}$, as well as modeling of chemical formulas of the polymer presented in the microfossils of Gleocapsomorphaprisca ${ }^{13}$.

As can be seen in Fig. 2, the basis of the structure is n-alkyl-substituted resorcinols, linked together with $\mathrm{C}-\mathrm{C}$ and $\mathrm{C}-\mathrm{O}$ bonds.

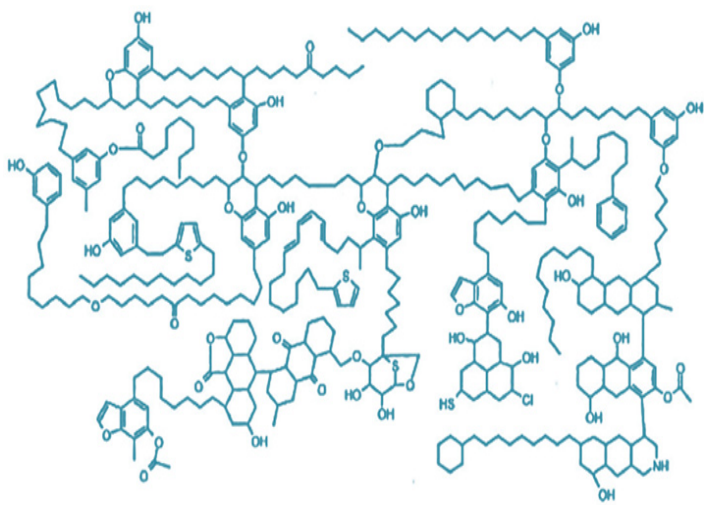

Fig. 2. Molecular structure of kukersite kerogen ${ }^{8}$

Given the extensive data on the simulation of the chemical structure of kerogen and due to the modern instrumental capabilities in obtaining information on the composition of the geopolymer of new samples, we can compare and arrive at far-reaching conclusions about the molecular structure of various types of kerogen, taking into account the features of the conditions under which they were formed. The building of the model of the macromolecular structure of the geopolymer is needed to visualize the contribution of individual groups of organic compounds to the composition of the kerogen matrix.

organic matter-rich Middle Volga oil shales are widespread in the EEP. In its eastern part, there are two largest basins of Upper Jurassic oil shales - the Volga basin and the Timan-Pechora basin, extending from the coast of the Barents and Pechora seas in the north to the Caspian Sea in the south Figure 3.

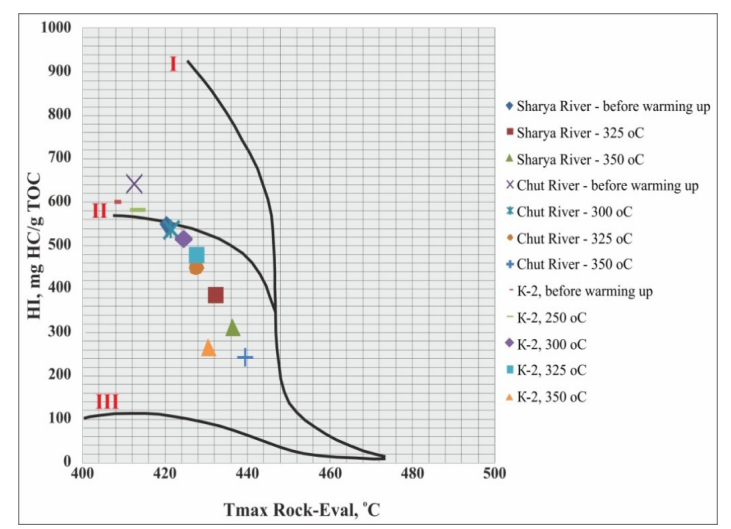

Fig. 3. Modified van Krevelen diagram of dependence of HI-Tmax of the organic matter samples of Middle Volga and Domanic shales

In terms of the composition of hydrocarbon components of bitumoid and products of desulfurization of its polar fraction, the main bio-producers that contributed to the composition of OM of Jurassic deposits are marine phytoplankton and, to a lesser extent, Embryophytes. One of the main differences in the composition of pyrolysis products of kerogens isolated from rocks comprising various concentrations of total organic carbon (TOC) is the increasing proportion of thiophenic structures as TOC increases. The presence of low-molecular or short-chain alkyl-substituted thiophenes with a linear carbon skeleton in pyrolysis products is due to the involvement of carbohydrate components of the starting organic matter in the processes of sulfur bonding in the stages of sedimentogenesis and diagenesis. Sulfurization of carbohydrates resulted in the formation of a poly-sulfur-bound structure that is part of kerogen, which, when pyrolyzed, yields thiophenes of similar structure. There was an increase in the content of long-chain $\mathrm{n}$-alkylthiophenes in the higher-molecular fraction. 
Sulfurization of the biochemical components of the starting $\mathrm{OM}$ can be considered as the main mechanism for the conservation of the OM in the deposits of the Jurassic basin. The optimal condition for the accumulation of Upper Jurassic shales was the area of overlapping the areas of the sea bottom, where intensive accumulation of organic detritus simultaneously proceeded at both sea levels - transgression and the normal one. Therefore, sediment deposition at the bottom of the sea basin was controlled by the location of the coastline, hydrodynamics and the slope of sea bottom.

The Domanic carbon deposits are confined to the Semiluki Horizon (corresponding to the Domanic horizon) of the Middle Frasnian substage. The Domanic horizon is consistently overlapping the Sargayev Horizon (D3f2). The quite wide prevalence and similarity of Domanic deposits (lithology, fauna, and geochemistry) of the Volga-Ural and Timan-Pechora basins allow speaking of a single Domanic facies formed under close conditions. The formation of deposits of domanik is connected with differentiation of the bottom of the paleobasin during the occurrence of reef and prereef facies. According to the carbon-petrographical data, the concentrate of the dispersed organic matter of domanik is as high as $80-100 \%$, is formed by collo alginite-collo chitinite, and chitinite is present in it in the amount of up to $22 \%$, while thallomo alginite is only single inclusions ${ }^{14}$. The hydrocarbon composition of bituminoids indicates a rather heterogeneous distribution of $n$ - and iso-alkanes in their composition. The most typical pattern in the distribution is a unimodal concentration maximum where hydrocarbons with the composition $\mathrm{C} 15-\mathrm{C} 21$ are predominant among $n$-alkanes and pristine is predominant among iso-alkanes ( $\mathrm{Pr} / \mathrm{Ph}$ ratio).

Cyanobacteria and marine phytoplankton made the main contribution, which is confirmed by the data of the hydrocarbon composition of bitumoids and kerogen. For example, the increased content of $n$-alkyl-containing compounds (homologous series of n-alkanes, n-alkenes-1, n-alkylbenzenes, ortho-n-alkyltoluenes, 2,5-disubstituted thiophenes, $\mathrm{n}$-alkylbenzthiophenes and n-alkylnaphthalenes) found in the aliphatic and aromatic fractions of products of pyrolysis of kerogen, indicates a high level of aliphaticity of the kerogen structure.

In terms of hydrocarbon-generation potential, the samples of OM of late-Devonian oil-source rocks have an excellent potential Figure 4.

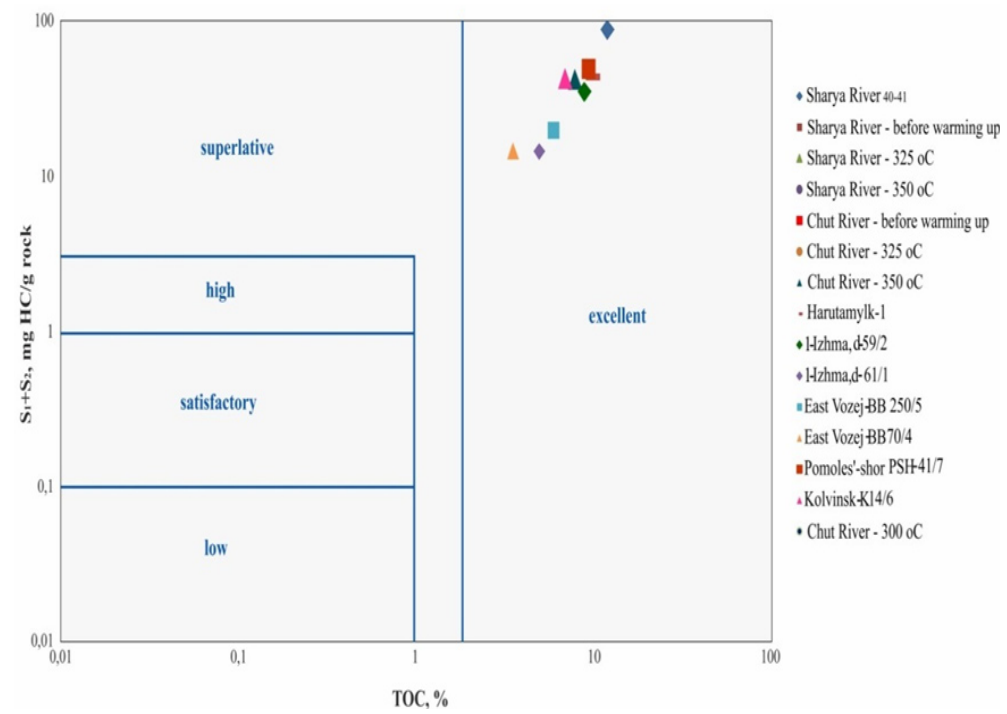

Fig. 4. Diagram of the change in the total generation potential $(\mathrm{S} 1+\mathrm{S} 2)$ of the total organic carbon TOC in the Domanic deposits

The level of catagenetic maturation of OM according to the values of the pyrolytic parameter Tmax of the samples under study corresponds to the maximum of hydrocarbon generation during pyrolysis, corresponding to values below $430^{\circ} \mathrm{C}$, i.e. having a number of samples at the beginning of the main area of oil formation. It should be noted that a minor part of the samples contains a more mature OM (Tmax $440-445^{\circ} \mathrm{C}$ ). The samples of Domanic deposits of the late Devonian have a low index of productivity $(P=0.01-0.24)$. 
Most of the samples under study are immature and correspond to values of Tmax $430^{\circ} \mathrm{C}$ and fall into the region of immature OM Fig. 5. The hydrocarbon composition of bituminoids studied by the gas chromatographic analysis indicates a rather heterogeneous distribution of $\mathrm{n}$ - and iso-alkanes in their composition. The most typical pattern in the distribution is a unimodal concentration maximum where hydrocarbons with the composition C15-C21 are predominant among $\mathrm{n}$-alkanes and pristine is predominant among iso-alkanes ( $\mathrm{Pr} / \mathrm{Ph}$ ratio). Based on the distribution of alkanes, we distinguished 15 groups ${ }^{15}$ with the most characteristic distinctive features, which were affected significantly by the initial composition of $\mathrm{OM}$, redox processes and the mineral composition of the rocks. In the diagram of the $\mathrm{Pr} / \mathrm{n}-\mathrm{C} 17 \mathrm{vs} \mathrm{Ph} / \mathrm{n}$ C18 ratios Fig. 6a, the predominantly mixed type of organic matter of the TPB Domanic deposits is clearly distinguished, which does not distinguish it from the type of OM of the Volga-Urals Domanic deposits Figure $6 b$.

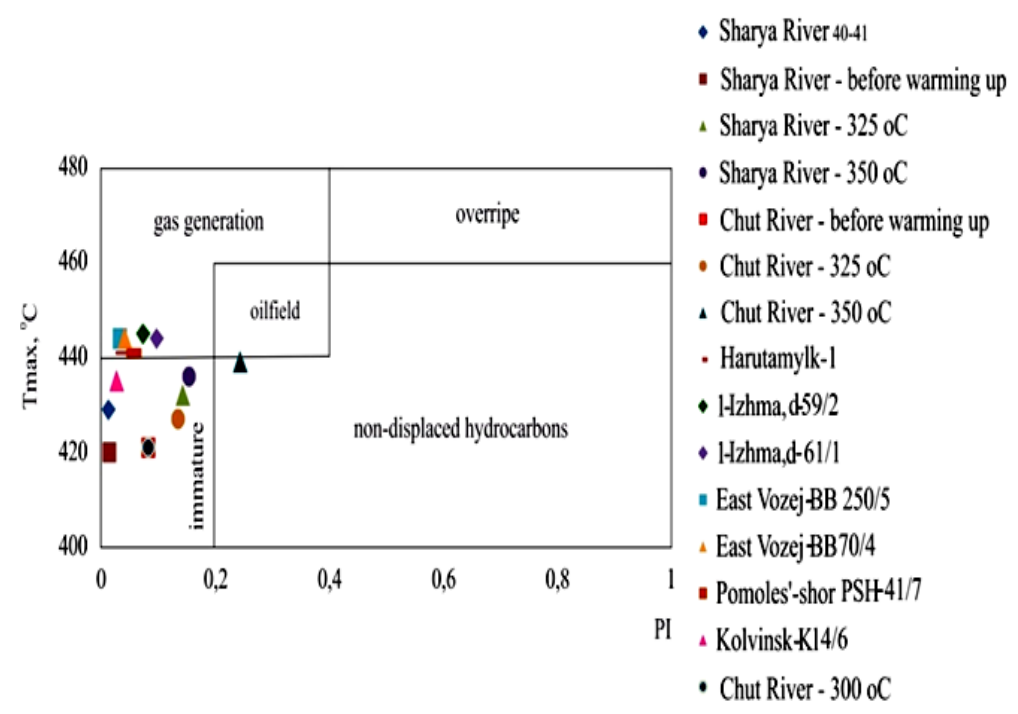

Fig. 5. Diagram of the dependence of the productivity index PI on the maximum pyrolysis temperature Tmax for the OM of the oil-source rocks of the TPB Domanic deposits

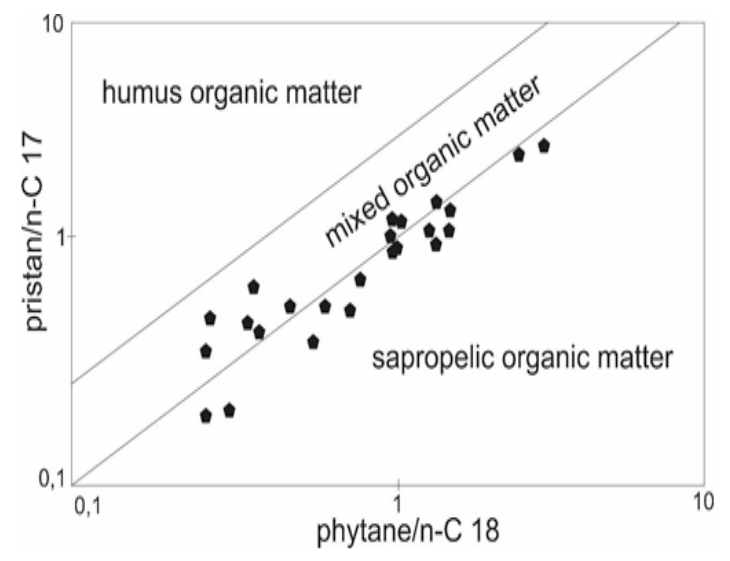

(a)

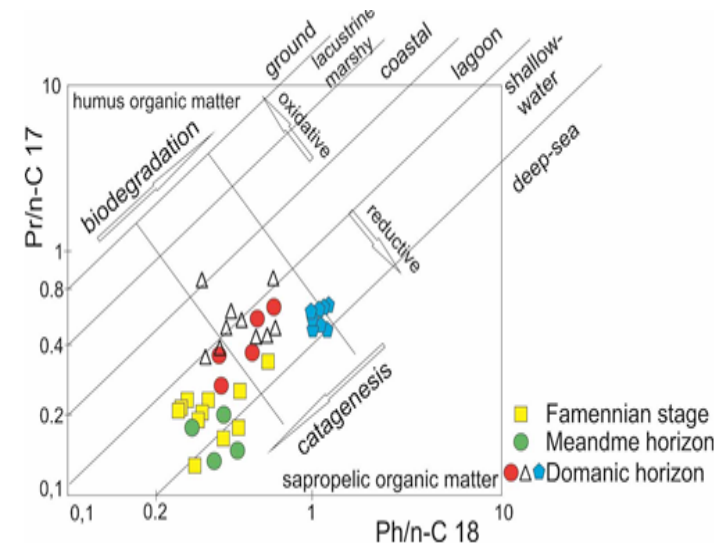

(b)

Fig. 6. Kennon-Kessow diagram for bitumoids of Domanic deposits:a) Timan-Pechora Basin ${ }^{15}$ and b) the Volga-Ural Basin ${ }^{16}$

Domanikites and domanikoids are found in almost all Phanerozoic systems Fig. 7, and they are also found in the Precambrian. It should be noted that in the Precambrian rocks, the contrast between bulk earth values in rocks and the content of organic matter in the domanikoid interlayers is very significant; and in rocks dated to the Cenozoic age, these differences are somewhat smoothed. 

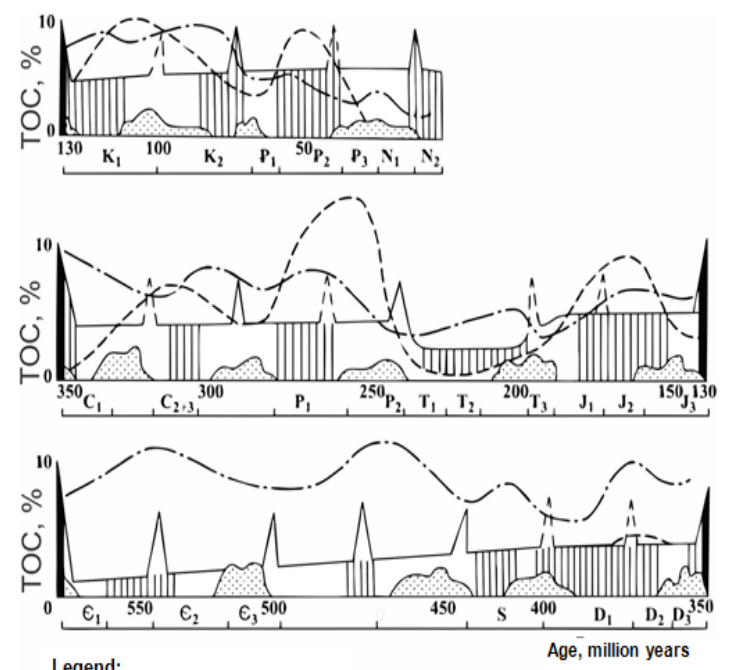

Legend:

$$
\begin{array}{ll}
\Lambda & \text { - Average concentrations TOC } \\
--- & \text { - Intensity of coal accumulation } \\
\hdashline \cdot- & \text { - Change in the sea area on the continents } \\
\Omega & \text { - folding phases } \\
\|\||||| & \text { - Stages of activation of rifting } \\
& \text { - Main epochs of accumulation of domanikites }
\end{array}
$$

Fig. 7. Distribution pattern of Domanic and domanikoid deposits in the Phanerozoic (according to S.G. Neruchev)

The study of the chemical structure of kerogenes of J3v2 oil shales (II-S type) and D3dm carbon rocks (II type) at the EEP allowed identifying the main distinctive features in the structure of individual structural components of these types of kerogen and refining the models of the fragment of their chemical structure. The J3v2 kerogen of oil shales is more highly aliphatic $(\mathrm{H} / \mathrm{Cpp}=1.32)$, the $\mathrm{n}$-alkyl constituents of which are bound to the matrix predominantly through sulfur and oxygen atoms, as compared to D3dm kerogen, whose average atomic ratio $(\mathrm{H} / \mathrm{Cp})=1.19$. Some of the oxygencontaining structures are found to be present in the Middle Volga kerogen as carbohydrate moieties and algaenan components, the alkyl chains in which are interlinked by ether bonds, and the structure of the sulfur-containing components can be represented as sulfide (polysulfide) bound n-alkyl structures, in pyrolysis of which low-molecular and high-molecular alkyl-substituted thiophenes, thienyland phenylthiophenes are formed. The average S/C value exceeding 0.04 classifies the Upper Jurassic kerogen as Type II-S. The predominant components in the composition of kerogen of Domanic rocks are lipid components, however, its lower aliphaticity is probably due to the higher maturity of $\mathrm{OM}$ and to the low ratio of $n$-alkyl structures to polyaromatic moieties, the formation of which is connected with the rearrangement of polyene and heteroatomic structures in catagenesis. The algaenan moieties in the OM of domanik, partially responsible for the formation of $n$-alkanes and $n$-alkenes in the pyrolysis of kerogen, are mainly bound by ester groups. The $\mathrm{S} / \mathrm{C}$ atomic ratio is below 0.04 , thus allowing to classify this kerogen as Type II. Both short-chain and long chain sulfur-bound n-alkyl structures are less typical of D3dm kerogen. The low values of the thiophene index, the presence of single homologous series of 2-methyl-5-n-alkylthiophenes and 2-n-alkylbenzothiophenes in the composition of pyrolysis products of kerogen, and the elemental composition of the initial geopolymer allow assessing the abundance of sulfur atoms in the local carbon structure and establishing the structure of the sulfur-bound moiety.

The nitrogen-containing structures of the kerogen of the Middle Volga and Domanic deposits are of different origin. The study of the composition of thermolysis products of kerogen from Kashpir oil shale pretreated with tetramethylammonium hydroxide showed that the main nitrogen-containing components are amino acids-glycine, alanine, phenylalanine, aspartic acid, and derivatives, possibly, of lysine or phenylamine ${ }^{17}$. It is thought that proteins comprising various amino acids are the most susceptible to destruction during the fossilization of the starting organic matter. However, some amine-containing structures can form destructionresistant polymers by degradation/recondensation ${ }^{3}$. The paper of the French researchers ${ }^{17}$ showed that the preservation of protein structures is due to their encapsulation by organic matter, and sulfur-rich macromolecules play an important role in this process ${ }^{17,18}$. The kerogen of the Upper Devonian deposits is characterized by the presence of chitin-containing structures that form part of the matrix as highly gelatinized chitinite ${ }^{19}$. The source of this group of $\mathrm{OM}$ microcomponents were the remains of organisms with a chitinous skeleton - mainly tentaculites ${ }^{20}$. Chitin as such is a chemically and biochemically stable polymer, which determines its preservation during geological time. Amino acids in Domanic kerogen have almost the same composition as in the Jurassic geopolymer. Glycine, leucine, alanine and proline are predominant ${ }^{21}$. Therefore, the set of experimental and literature data obtained 
allowed us to study in detail the structure of individual structural components and the features of a fragment of the chemical structure of kerogen. The obtained model of the chemical structure of kerogen of Upper Jurassic deposits has a number of similar and distinctive features if compared to the structure of kerogen of Upper Devonian deposits. The kerogen of Upper Jurassic deposits is a highly aliphatic polymer, whose n-alkyl constituents are bound to the matrix with sulfur and oxygen atoms. The increased content of oxygen-containing structures in it is probably due to the effective conservation of carbohydrate components in diagenesis, and to the saturation with ether bonds typical of the initial organic matter of Algaenan shales. The presence of a carbohydrate component is confirmed by the high contents of "linear" short-chain thiophenes in pyrolysis products. The S/C values exceeding 0.04 classify the Upper Jurassic kerogen as Type II-S. The main sulfur-containing moieties of the geopolymer are sulfide(polysulfide)bound n-alkyl structures. Nitrogen is mainly present in the amino acid constituents of kerogen. Lipid moieties mainly dominate in the kerogen of Domanic deposits. The content of $n$-alkanes and n-alkenes in pyrolysis products of kerogen of Domanic deposits is twice as high as that in the kerogen of the Volga shales. The formation of $n$-alkanes and n-alkenes is partially due to the pyrolysis destruction of the algaenan structural moieties found in the geopolymer. The n-alkyl structures of the algaenans of domanik are allegedly bound mainly through ester bonds, as evidenced by the increased content of $\mathrm{CO}_{2}$ released during pyrolysis as compared to $\mathrm{CO}$. The $\mathrm{S} / \mathrm{C}$ atomic ratio is below 0.04 , thus allowing to classify this kerogen as Type II. Both short-chain and long chain sulfur-bound n-alkyl structures are less typical of D3dm kerogen. The low level of sulfurization of kerogen of Upper Devonian deposits is confirmed by low values of the thiophene index. The increased nitrogen content in such kerogen is explained by the presence of highly gelatinized chitinite, the starting material of which was the chitinous shells of tentaculites. Analysis of gaseous pyrolysis products of kerogen showed a high content of water released, probably, due to the elimination of hydroxyl groups of phenolic type. Some aromatic structures are formed directly in the kerogen itself in diagenesis and continue to form during further processes of transformation of OM, while some other aromatic structures are inherited from the starting organic matter. For example, the "aromaticity" of the kerogen of the Volga shales is quite likely connected with lignin and its decay products included in the kerogen, the presence of carotenoid structures such as isorenirate derivatives. In the Domanic type of kerogen, the aromatic part is the products of the transformation of isorenirate, rhenierate or rheniurpurpurin ${ }^{22}$, and mainly di- and polyaromatic nuclei.

Therefore, the ideas about the chemical structure of kerogen obtained from the elemental analysis, the analysis of the composition of pyrolysis products, data on the composition of the gas components of the kerogen, and also obtained by search of literature data on structural fragments of the starting organic matter and geopolymer, confirm that the kerogen structure is influenced by the composition of the starting $\mathrm{OM}$ and the conditions of sedimentogenesis and the further formation of the geopolymer in diagenesis $22-31$.

\section{CONCLUSION}

The study of the chemical structure of kerogenes of J3v2 oil shales (II-S type) and D3dm carbon rocks (II type) of the EEP allowed identifying the main distinctive features in the structure of individual structural components of these types of kerogen and refining the models of the fragment of their chemical structure. The J3v2 kerogen of oil shales is more highly aliphatic (H/QF = 1.32), the n-alkyl constituents of which are bound to the matrix predominantly through sulfur and oxygen atoms, compared to D3dm kerogen with an average atomic ratio $(H / Q p)=1.19$. Some of the oxygencontaining structures are found to be present in the Middle Volga kerogen as carbohydrate moieties and algaenan components, the alkyl chains in which are interlinked by ether bonds, and the structure of the sulfur-containing components can be represented as sulfide(polysulfide)bound n-alkyl structures, in pyrolysis of which low-molecular and high-molecular alkyl-substituted thiophenes, thienyland phenylthiophenes are formed. The average S/C value exceeding 0.04 classifies the Upper Jurassic kerogen as Type II-S.

The predominant components in the composition of kerogen of Domanic rocks are lipid components, however, its lower aliphaticity is 
probably due to the higher maturity of $\mathrm{OM}$ and to the low ratio of n-alkyl structures to polyaromatic moieties, the formation of which is connected with the rearrangement of polyene and heteroatomic structures in catagenesis. The algaenan moieties in the OM of domanik, partially responsible for the formation of $n$-alkanes and n-alkenes in the pyrolysis of kerogen, are mainly bound by ester groups. The $\mathrm{S} / \mathrm{C}$ atomic ratio is below 0.04 , thus allowing to classify this kerogen as Type II. Both short-chain and long chain sulfur-bound n-alkyl structures are less typical of D3dm kerogen. The low values of the thiophene index, the presence of single homologous series of 2-methyl-5-n-alkylthiophenes and 2-n-alkylbenzothiophenes in the composition of pyrolysis products of kerogen, and the elemental composition of the initial geopolymer allow assessing the abundance of sulfur atoms in the local carbon structure and establishing the structure of the sulfur-bound moiety.

\section{ACKNOWLEDGMENT}

This work was supported by the Ministry of Education and Science of the Russian Federation within the framework of the Task No. 10.6569.2017/ BP for the implementation of research work (the basic part of the state task in the area of scientific activity).

\section{REFERENCE}

1. Dobryanskij, A.F. Nedra. Leningr. otdelenie, 1962, 17-19.

2. Vassoevich, N.B.; Kontorovich A.Eh.; Lopatin, N.V. M.: Izd-vo MGU., 1974, 13 - 15.

3. Tisso, B. Obrazovanie i rasprostranenie nefti / M.: Mir., 1981, 504.

4. Burlingame, A.L; Haug, P.A.; Schnoes, B.R.; Simoneit B.R. Oxford: Pergamon Press. 1969, 85-128.

5. Behar, F. Organic Geochemistry., 1987, 11(1), 15-24.

6. Rullkotter, J.; Michaelis, W. Organic Geochemistry., 1989, 16, 829 - 852.

7. Siskin, M. Kluwer Academic Publishers, Dordrecht., 1995, 143 - 158.

8. Lille, U. Fuel., 2003, 82, 799-804.

9. Klesment, I. Fuel., 1980, 59, 117 - 122.

10. Derenne, S. Organic Geochemistry., 1992, 19, 299 - 313.

11. Fowler, M. G. Organic Geochemistry., 1984, 6, $105-114$.

12. Douglas, A. G. Geochim. et Cosmochim. Acta., 1991.

13. Blokker, P. Geochim Cosmochim Acta., 2001, 65(6), 885 - 900.

14. Neruchev, S. G. L.: Nedra., 1986, 247.

15. Kiryuhina, T. A.; Bol'shakova, M. A.; Stupakova, A. V.; Korobova, N. I.; Pronina N. V. Georesursy., 2015, 2(61), 87 - 99.

16. Stupakova, A. V. Georesursy., 2015, 2(61), 77 - 86.

17. Mongenot, Th.; Riboulleae, A.; GarcetteLepecq, Organic Geochemistry., 2001, 32, 199 - 203.
18. Nguyen, R. T. ACS Symposium Series., 1998, 707, $89-112$.

19. Yudovich, Y.E. L.: Nauka., 1988, 272.

20. Geohimiya goryuchih slancev, Tez. Dokl. 3-go Vses. soveshch. Tallin., 1982, 248.

21. Anishchenko, L. A. Syktyvkar: Geoprint., 2007, 95 - 116.

22. Bushnev, D. A. Neftekhimiya., 2002, 42(5), $325-339$.

23. Kerimov, V.Y.; Rachinsky, M.Z.; Mustaev, R.N.; Osipov, A.V. Doklady Earth Sciences., 2017, 476(1), 1066-1068.

24. Guliev, I.S.; Kerimov, V.Yu.; Mustaev, R.N. Doklady Earth Sciences., 2016, 471(1), 1109-1112

25. Kerimov, V.Y.; Gordadze, G.N.; Lapidus, A.L.; Giruts, M.V.; Mustaev, R.N.; Movsumzade, E.M.; Zhagfarov, F.G; Zakharchenko, M.V. Solid Fuel Chemistry., 2018, 52(2), 128-137.

26. Kerimov, V.Yu; Rachinsky, M.Z. Doklady Earth Sciences., 2016, 471(1), 1123-1125.

27. Kerimov, V.Yu.; Mustaev, R.N.; Bondarev, A.V. Orient. J. Chem., 2016, 32(6), 3235-3241.

28. Lapidus, A.L.; Kerimov, V.Y.; Mustaev, R.N.; Movsumzade, E.M.; Zakharchenko, M.V. Oil Shale., 2018, 35(2), 113-127.

29. Kerimov, V.Yu.; Lapidus, A.L.; Yandarbiev, N.Sh.; Movsumzade, E.M.; Mustaev, R.N. Solid Fuel Chemistry., 2017, 51(2), 122-130.

30. Kerimov, V.Yu.; Mustaev, R.N.; Yandarbiev, N.Sh.; Movsumzade, E.M. Orient. J. Chem., 2017, 33(2), 879-892.

31. Rachinsky, M.Z.; Kerimov, V.Yu. Fluid dynamics of oil and gas reservoirs, Scrivener Publishing Wiley., 2015, 613. 